\title{
CHARACTERIZATION AND CONTROL OF A STRONTIUM FERRITE MOTOR
}

\author{
Marcos A. A. Costa, Edgar R. Braga-Filho, Antonio M. N. Lima \\ Universidade Federal de Campina Grande - UFCG \\ Programa de Pós-Graduação em Engenharia Elétrica - PPgEE \\ Campina Grande - PB, Brazil \\ e-mails: marcos.costa@ee.ufcg.edu.br, \{edgar,amnlima\}@dee.ufcg.edu.br
}

\begin{abstract}
Exploiting the flux concentration configuration is a good alternative for designing a relatively low cost synchronous motor based on ferrite magnets. This paper discusses the design of a motor drive system based on a three-phase permanent magnet motor in which both the use of low cost ferrite and minimization of cogging torque have been adopted as design criteria. The dynamic modeling, parameter identification, and experimental characterization of the motor as well as the overall control system design have been performed. Simulation and experimental results are presented to demonstrate the correctness of the methodology and the feasibility of proposed motor drive solution and its related feedback control laws.
\end{abstract}

Keywords - AC motor drive system, Characterization of permanent magnet motor, Feedback control system, Permanent magnet motor modeling, Permanent magnet motor.

\section{INTRODUCTION}

The development of the power electronics together with the availability of new types of magnetic alloys have allowed the usage at industrial scale of permanent magnet motors. This fact opens new perspectives for applying this type of electromechanical converter in quite diverse types of configurations, all of them requiring the use of computer aided design tools to investigate how the physical arrangement of the magnets in the rotor of the device affects the energy conversion process. The most popular among these configurations are the surface design (SPM) and transverse design (IPM). In the surface design, the permanent magnets are placed along the outer surface of the rotor whereas, for the transverse design the permanent magnets are inserted in the rotor along its radius. Transverse placed permanent magnets provide good mechanical resistance against centrifugal forces created when the rotor rotates at nominal speed [1]. Besides the mechanical robustness the transverse design allows one to use ceramic magnets that exhibit low energy density being relatively cheap when compared to rare earth magnets. The transverse design promotes magnetic flux concentration and consequently one may obtain, even for a low energy density magnet, a relatively high level of magnetic induction at the airgap and thus a high torque density. In the face of the so called rare earth magnet crisis [2] these are quite important characteristics since

Manuscript received 13/02/2014; revised 01/06/2014; accepted for publication 01/12/2014, by recommendation of the Special Section Editor Mário Lúcio da Silva Martins it provides an alternative for the design of high performance and low cost permanent magnet motors.

This paper discusses the design of motor drive system based on strontium ferrite $\left(\mathrm{SrFe}_{12} \mathrm{O}_{19}\right)$ permanent magnet motor in which the magnets are placed transversely along the rotor radius. As it will be shown, such electromagnetic configuration leads to mathematical formulation that is quite different from the standard salient pole permanent magnet motor model. However, despite these differences, the conceptual basis for the proposed control laws is quite similar to the standard cascade strategy where the reference current for the $q$-axis stator current controller is provided at the output of the speed controller and the reference current for the $d$-axis current controller is kept zero [3]-[5]. The idea behind this decision is to verify the robustness of the standard control strategy and determine whether it will be necessary to employ more sophisticated control laws. Simulation and selected experimental results are presented to demonstrate the correctness of the methodology as well as the feasibility of proposed motor design and its related control strategy.

\section{MOTOR DESIGN}

Interior permanent magnet motors (IPM) are designed such that the magnets are placed transversely along the rotor radius [6]-[8]. This type of motor is used in high performance applications that demand high massive power [9]-[11] and high volumetric efficiency [12]. The design procedure adopted for the motor studied in this paper exploits the use of computer aided tools based on the finite element method. The details of the design procedure can be found in [9]. In the present paper, due to space limitations, the proposed modeling, parameter estimation and control design methodology will be applied only to the first built prototype for which the cogging torque reduction was not implemented. Figure 1 shows a photograph of the actual IPMS prototype. Exploded views of all the parts that compose the stator and the rotor of the prototype are shown in Figure 2. The IPM motor design data are given in Table I; from now on the machine prototype will be refereed as IPMS.

\section{MOTOR MODELING}

In the design of motor drive systems, the standard approach is to employ the Park's model for representing the dynamic behavior of the electromechanical converter. The modeling approach adopted in the present work can be considered as a semi-empirical one. Indeed, the derivation of the proposed model, up to certain point, follows the same procedure adopted in the modeling of a salient pole permanent magnet 
TABLE I

IPM Motor Design Data - Strontium Ferrite: $\mathrm{SrFe}_{12} \mathbf{O}_{19}$ Magnets.

\begin{tabular}{ccc}
\hline Quantity & Symbol & Value/Unit \\
\hline Rated power & $P_{n}$ & $250 \mathrm{~W}$ \\
\hline Rated current & $I_{a}$ & $2.5 \mathrm{~A}$ \\
\hline Number of magnetic poles pairs & $p$ & 4 \\
\hline Number of stator phases & $m$ & 3 \\
\hline Number of stator slots & $N_{r h}$ & 24 \\
\hline Stator pole pitch & $\tau_{p}$ & $34.95 \mathrm{~mm}$ \\
\hline Axial length & $L$ & $90 \mathrm{~mm}$ \\
\hline External diameter & $D_{o}$ & $120 \mathrm{~mm}$ \\
\hline Core height & $h_{n}$ & $5 \mathrm{~mm}$ \\
\hline Teeth height & $h_{t}$ & $10 \mathrm{~mm}$ \\
\hline Magnet sizes & $l_{m} / h_{m} / w_{m}$ & $8.8 / 25 / 42 \mathrm{~mm}$ \\
\hline Remanence & $B_{r}$ & $0.38 \mathrm{Tesla}$ \\
\hline Air gap & $g_{m e c}$ & $0.3 \mathrm{~mm}$ \\
\hline Aspect ratio & $\gamma$ & $2 / 3$ \\
\hline
\end{tabular}

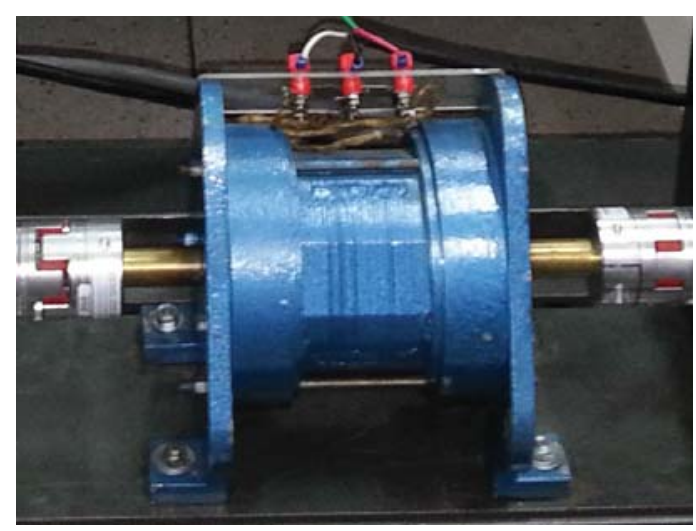

Fig. 1. Photograph of the IPMS prototype.

motor. The basic difference is related to the refinement of the mathematical representation used to describe the spatial dependencies of the self and mutual inductances and the magnetic flux due to the permanent magnets. The details regarding the application of the physical laws as well as the step by step model derivation are not presented due to space limitations and can be found in [13].

Determining the model parameters is quite important for designing the feedback control laws. There are several techniques for determining the mechanical and electrical parameters of permanent magnet motors [10],[12],[14]-[20]. In the present paper a locked rotor technique was adopted for determining the angular profile of the stator inductances; the rotor must be locked at different angular positions. The characterization of the magnetic flux linkage will be performed based on the voltage induced at the stator windings when the machine operates as a generator. Experimental results obtained from those two tests will be presented further on. Based on such experimental results, which are presented in section $\mathrm{V}$, the following mathematical model was adopted for representing the dynamics of the IPMS prototype:

$$
\begin{aligned}
\mathbf{V}_{d q} & =\mathbf{R}_{s} \mathbf{I}_{d q}+\mathbf{L}_{d q} \frac{d}{d t} \mathbf{I}_{d q}+\mathbf{U}_{d q} \\
c_{e} & =\frac{p}{2} \mathbf{I}_{d q}^{T} \mathbf{L}_{c} \mathbf{I}_{d q}+p \mathbf{I}_{d q}^{T} \boldsymbol{\Lambda}_{r d q}^{\prime}
\end{aligned}
$$

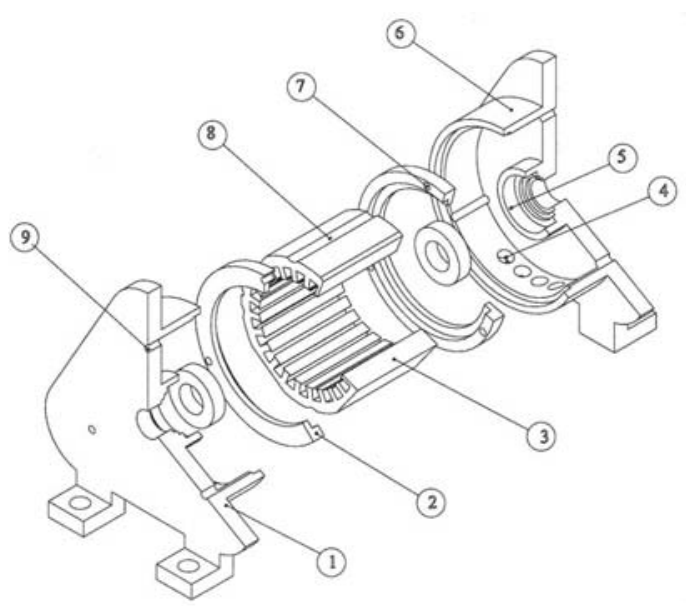

(a) The principal elements of the stator are: back cover (1), locking ring (2), stator assembly (3), evacuation holes (4), front cover (5), handle (6), hole guide (7), (9) and weld seam (8).

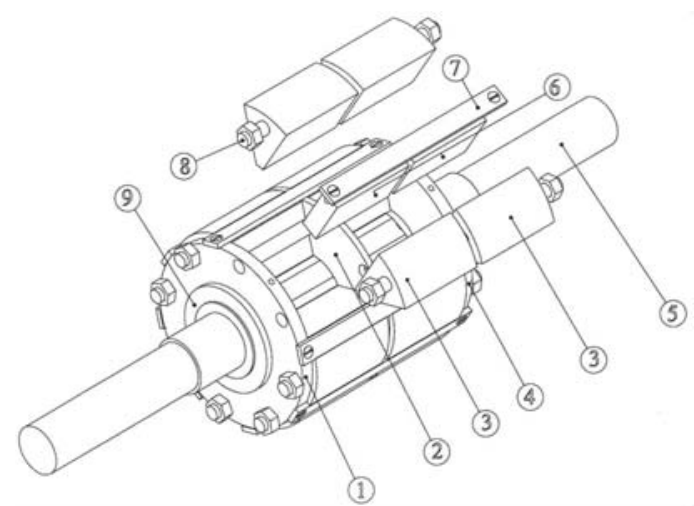

(b) The principal elements of the rotor are: front and back rings (1), (4), spacing ring (2), polar pieces block (3), shaft (5), magnetized pieces (6), interpolar spacer (7), extenders fixing (8), and retaining flange (9).

Fig. 2. Exploded views of the stator and rotor showing the principal elements of the IPMS.

and

$$
J \frac{d}{d t} \omega_{r}=p\left(c_{e}-c_{m}\right)
$$

where

$$
\begin{gathered}
\mathbf{U}_{d q}=\omega_{r}\left(\mathbf{L}_{c} \mathbf{I}_{d q}+\mathbf{\Lambda}_{r d q}^{\prime}\right) \\
\mathbf{V}_{d q}=\left[\begin{array}{ll}
v_{d} & v_{q}
\end{array}\right]^{T} \\
\mathbf{I}_{d q}=\left[\begin{array}{ll}
i_{d} & i_{q}
\end{array}\right]^{T} \\
\mathbf{R}_{s}=\left[\begin{array}{cc}
r_{s} & 0 \\
0 & r_{s}
\end{array}\right] \\
\mathbf{L}_{d q}=\left[\begin{array}{cc}
l_{d}\left(\theta_{r}\right) & 0 \\
0 & l_{q}\left(\theta_{r}\right)
\end{array}\right]
\end{gathered}
$$




$$
\begin{gathered}
\mathbf{L}_{c}=\left[\begin{array}{cc}
0 & l_{c}\left(\theta_{r}\right) \\
l_{c}\left(\theta_{r}\right) & 0
\end{array}\right] \\
\mathbf{\Lambda}_{r d q}^{\prime}=\frac{d \boldsymbol{\Lambda}_{r d q}}{d \theta_{r}}=\left[\begin{array}{c}
\lambda_{r d}^{\prime}\left(\theta_{r}\right) \\
\lambda_{r q}^{\prime}\left(\theta_{r}\right)
\end{array}\right] \\
l_{d}\left(\theta_{r}\right)=L_{d}+l_{d h} \cos \left(6 \theta_{r}\right) \\
l_{q}\left(\theta_{r}\right)=L_{q}+l_{q h} \cos \left(6 \theta_{r}\right) \\
l_{c}\left(\theta_{r}\right)=l_{c d c}+l_{c a c} \cos \left(6 \theta_{r}\right) \\
\lambda_{r d}^{\prime}\left(\theta_{r}\right)=\lambda_{\mathrm{PM} 6 d} \sin \left(6 \theta_{r}\right)+\lambda_{\mathrm{PM} 12 d} \sin \left(12 \theta_{r}\right) \\
\lambda_{r q}^{\prime}\left(\theta_{r}\right)=\lambda_{\mathrm{PM} q}+\lambda_{\mathrm{PM} 6 q} \cos \left(6 \theta_{r}\right)+\lambda_{\mathrm{PM} 12 q} \cos \left(12 \theta_{r}\right) .
\end{gathered}
$$

In the above equations $\mathbf{V}_{d q}$ is $d$ - and $q$-axis voltages, $\mathbf{I}_{d q}$ the $d$ - and $q$-axis currents, $c_{e}$ electromagnetic torque, $c_{m}$ mechanical load, $\omega_{r}$ the electrical angular rotor speed, $p$ number of pair poles, $\mathbf{R}_{s}$ the stator resistance, $\mathbf{L}_{d q}$ the $d$ and $q$ - axis inductances, $\mathbf{L}_{c}$ the coupling inductances, $\boldsymbol{\Lambda}_{r d q}^{\prime}$ the $d$ - and $q$ - axis magnetic flux linkages, $J$ the moment of inertia. Indeed, the experimental results have shown that by adding more harmonic terms in the mathematical expressions used to specify the spatial dependencies of the self and mutual inductances as well as the magnetic flux linkage with respect to the standard salient pole synchronous motor model equations one may obtain a quite good representation for the IPMS.

The above model equations have been expressed in coordinates of a synchronous reference frame. To express the three-phase quantities in synchronous coordinates one must apply the following transformation matrices

$$
\begin{aligned}
T_{\alpha \beta} & =\sqrt{\frac{2}{3}}\left[\begin{array}{ccc}
1 & -\frac{1}{2} & -\frac{1}{2} \\
0 & \frac{\sqrt{3}}{2} & -\frac{\sqrt{3}}{2}
\end{array}\right] \\
T_{d q} & =\left[\begin{array}{cc}
\cos \left(\theta_{r}\right) & -\sin \left(\theta_{r}\right) \\
\sin \left(\theta_{r}\right) & \cos \left(\theta_{r}\right)
\end{array}\right] .
\end{aligned}
$$

Figure 3 shows a simplified representation for the permanent magnet motor studied in this paper. This illustration presents the permanent magnets placed transversely along the rotor radius, eight magnetic poles, where $\theta_{m}\left(\theta_{r}=p \theta_{m}\right)$ is the rotor angular position in mechanical radians. Thus, the $d q$-axes are spaced electrically by $\pi / 2$ degrees as represented in a polar pitch and mechanically by $\pi / 8$ degrees. The parameter values are provided in the section where it presents and discusses the experimental results.

\section{CONTROL STRATEGY}

The design of a control strategy is usually based on a mathematical model that suitably represents the dynamics of the system under consideration. High performance ac motor drive systems are usually based on field orientation concepts. Figure 4 shows the block diagram of the speed control scheme. The outer loop is for regulating the mechanical speed control and the inner loop for stator current regulation. The control

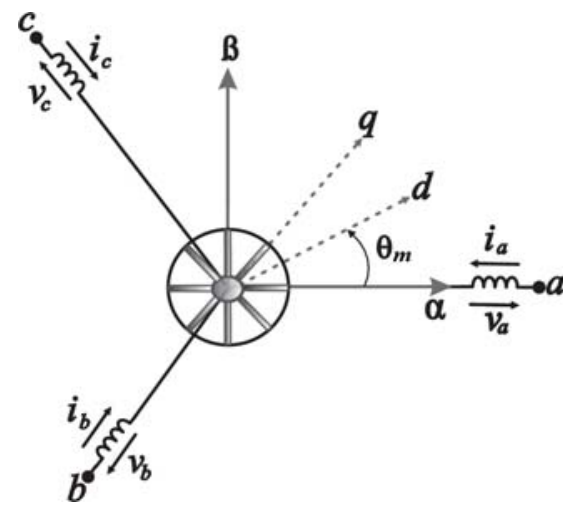

Fig. 3. Simplified representation for the permanent magnet motor.

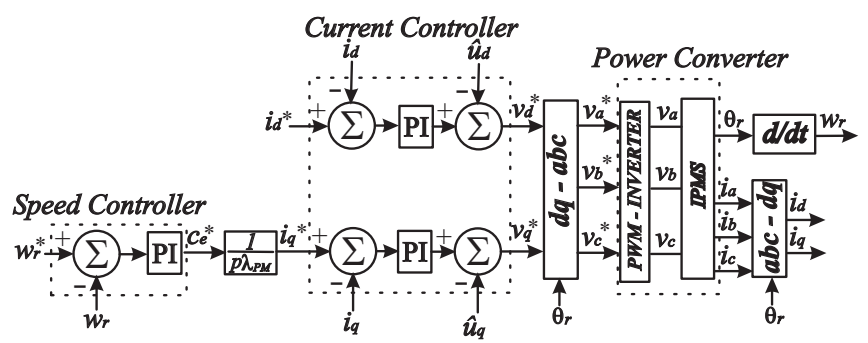

Fig. 4. Block diagram of the control strategy for ac motor drive system.

laws are implemented in the rotor flux reference frame an thus the $d$-axis shown in Figure 3 must be aligned with $\theta_{r}$. Pulse width modulation is used for generating the stator supply voltage and the control strategy is composed of three linear proportional integral controllers. The output of speed controller provides, $i_{q}^{*}$, the $q$-axis reference current (an image of the required electromagnetic torque) and thus it is cascaded with the $q$-axis current controller. The $d$-axis reference current is set to zero, $i_{d}^{*}=0$, since the magnetic excitation is provided by the rotor magnets and there is no field weakening. The outputs of the $d$-and $q$-axis current controller are compensated by $\hat{u}_{d}$ and $\hat{u}_{q}$, respectively; these terms represent the effect of the back electromotive force.

\section{A. D- and Q-axis Current Control}

For determining the gains of the current controllers the strategy one may consider that the mechanical time constant is quite large when compared to the electrical ones; thus, for the design of the electrical control loops one may assume that the terms associated with the mechanical sub-system can be treated as slowly time varying quantities. Besides, provided by the decoupling of the $d$ - and $q$-axis, the current control can be achieved with two independent PI regulators since the current/voltage relationship can be described by a first order model and unity gain is a requirement for the closed-loop. The Laplace transform of the voltage equation is given by:

$\mathbf{V}_{d q}(s)=\left[\begin{array}{cc}s l_{d}\left(\theta_{r}\right)+r_{s} & 0 \\ 0 & s l_{q}\left(\theta_{r}\right)+r_{s}\end{array}\right] \mathbf{I}_{d q}(s)+\mathbf{U}_{d q}(s)$.

The back electromotive forces $\left(\mathbf{U}_{d q}(s)\right)$ depend on the motor speed and will be considered as disturbances. Defining the 
voltage

$$
\mathbf{V}_{d q}^{\prime}(s)=\mathbf{V}_{d q}(s)-\mathbf{U}_{d q}(s)
$$

leads to

$$
I_{\{d, q\}}(s)=\frac{1}{l_{\{d, q\}} s+r_{s}} V_{\{d, q\}}^{\prime}(s)
$$

where the $\theta_{r}$ argument was dropped to simplify the notation, and the PI current controller is given by

$$
\mathbf{G}_{d q}(s)=\left[\begin{array}{cc}
K_{p d} & 0 \\
0 & K_{p q}
\end{array}\right]+\frac{1}{s}\left[\begin{array}{cc}
K_{i d} & 0 \\
0 & K_{i q}
\end{array}\right]
$$

where $K_{p\{d, q\}}$ and $K_{i\{d, q\}}$ denote the proportional and the integral gains, respectively. The closed-loop transfer function from the reference current to the actual stator current is given by

$$
\frac{I_{\{d, q\}}(s)}{I_{\{d, q\}}^{*}(s)}=\frac{\frac{K_{p\{d, q\}} s+K_{i\{d, q\}}}{l_{\{d, q\}}}}{s^{2}+\frac{K_{p\{d, q\}}+r_{s}}{l_{\{d, q\}}} s+\frac{K_{i\{d, q\}}}{l_{\{d, q\}}}} .
$$

These gains are determined by $d$-axis: $K_{p d}=\alpha_{i d} r_{s}, K_{i d}=$ $K_{p d} \frac{r_{s}}{l_{d}}, q$-axis: $K_{p q}=\alpha_{i q} r_{s}, K_{i q}=K_{p q} \frac{r_{s}}{l_{d}}$ where $\alpha_{i d}$ and $\alpha_{i q}$ are specified in terms of the pole location for the respective closed-loop. For this design rule, only the average values of the self inductances of the $d$-axis and $q$-axis, i.e., $L_{d}$ and $L_{q}$, have been considered, as explained further on.

\section{B. Speed Controller}

For determining the gains of the speed controller one may consider that the stator currents are both regulated, i.e.,

$$
\begin{aligned}
& i_{d}(t)=i_{d}^{*}, \forall t>0 \\
& i_{q}(t)=i_{q}^{*}, \forall t>0
\end{aligned}
$$

in this case the electromagnetic torque generated by the motor, $c_{e}$, is determined by $i_{q}^{*}$. Thus, from the point of view of the mechanical load, one may consider the permanent magnet motor as a torque generator. The Laplace transform of the mechanical sub-system is given by

$$
p\left(C_{e}(s)-C_{m}(s)\right)=J s \Omega_{r}(s) .
$$

Now, defining the net torque as

$$
C_{e}^{\prime}(s)=C_{e}(s)-C_{m}(s)
$$

the transfer function used in the design of the speed control becomes

$$
\Omega_{r}(s)=\frac{p}{J s} C_{e}^{\prime}(s) .
$$

The PI controller for the speed loop is given by

$$
G_{w}(s)=K_{p w}+\frac{K_{i w}}{s}
$$

where $K_{p w}$ and $K_{i w}$ denote the proportional and the integral gains, respectively. Thus, the closed-loop transfer function will be given by

$$
\frac{\Omega_{r}(s)}{\Omega_{r}^{*}(s)}=\frac{\left(K_{p w} s+K_{i w}\right)(p / J)}{s^{2}+(p / J) K_{p w} s+(p / J) K_{i w}} .
$$

In this case the controller gains are given by $K_{p w}=$ $2 J \alpha_{w}, K_{i w}=\frac{K_{p w}^{2}}{4 J}$ where $\alpha_{w}$ is specified in terms of the displacement of the real pole.
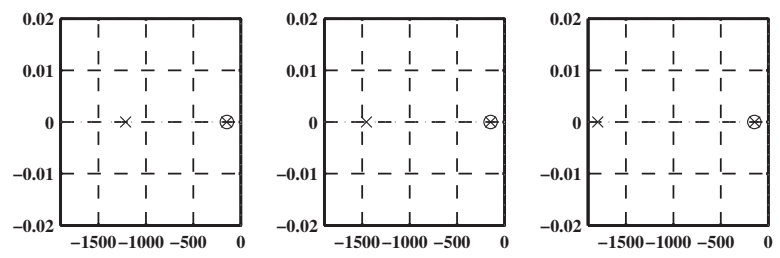

(a) $l_{d}\left(\theta_{r}\right)=L_{d}+l_{d h}$

(b) $l_{d}\left(\theta_{r}\right)=L_{d}$

(c) $l_{d}\left(\theta_{r}\right)=L_{d}-l_{d h}$
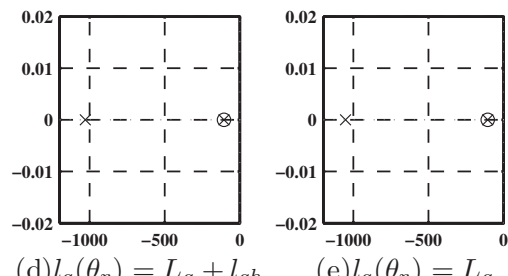

(e) $l_{q}\left(\theta_{r}\right)=L_{q}$

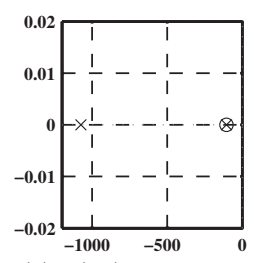

(f) $l_{q}\left(\theta_{r}\right)=L_{q}-l_{q h}$

Fig. 5. Poles $(x)$ and zeros (o) for the three different operating conditions regarding the inductances $l_{d, q}\left(\theta_{r}\right)$ : (a) Maximum values, (b) dc component, (c) minimum value of d-axis inductance, (d) Maximum values, (e) dc component, (f) minimum value of q-axis inductance.
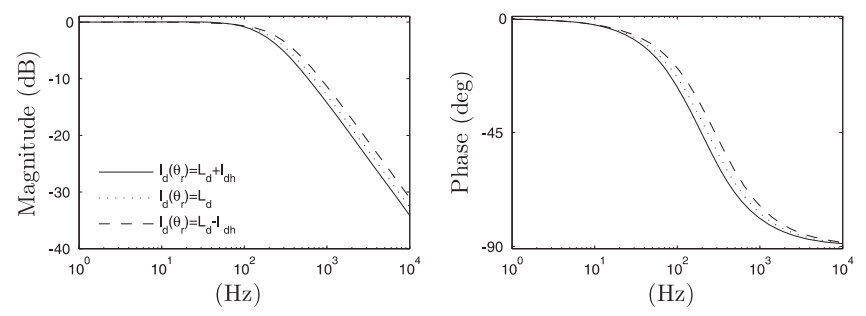

(a)
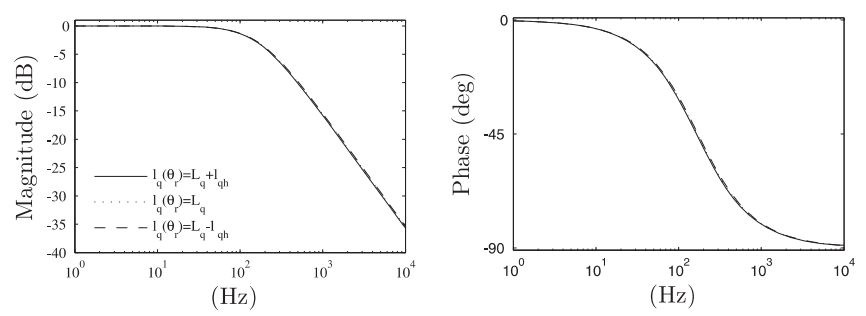

(b)

Fig. 6. Bode's diagram for the three different operating conditions regarding the inductances $l_{d, q}\left(\theta_{r}\right)$ : (a) Maximum $L_{d}+l_{d h}$, dc component $L_{d}$ and the minimum $L_{d}-l_{d h} \mathrm{~d}$-axis inductance, (b) Maximum $L_{q}+l_{q h}$, dc component $L_{q}$ and the minimum $L_{q}-l_{q h}$ q-axis inductance.

\section{PI Current Controllers}

Figure 5 shows the pole-zero maps for the transfer function given in (22) at three different conditions regarding the inductances profile $l_{d, q}\left(\theta_{r}\right)$ (see expression in section III), i.e., the maximum $L_{d, q}+l_{d h, q h}$, the dc component $L_{d, q}$ and the minimum $L_{d, q}-l_{d h, q h}$. By observing this figure one can see that pole-zero maps remain basically unchanged when the inductances varies. Figure 6 shows the Bode's diagram for the same conditions. 
Based on those results one may use constant gains in the current controllers since the differences observed at polezero maps at the three operating conditions can be neglected. Thus, for simplicity, the dc components of the $d$-axis and $q$ axis inductances for determining the controller gains will be used; the correctness of this decision will be demonstrated by numerical simulation and also experimentally in the following sections.

\section{Control Law Discretization}

The discrete time implementation of the stator current controllers and speed controller was obtained by using the Tustin discretization method. Although not mandatory, for simplicity the same sampling time was used in the implementation of the three controllers. The discrete transfer function of the controller is given by

$$
G_{x}(z)=K_{p x}+\frac{T_{s}}{2} K_{i x} \frac{z+1}{z-1}
$$

where $x \in\{d, q, w\}, d$ and $q$ denoting the $d$-axis current controller and $q$-axis current controller, respectively and $w$ standing for the speed controller. By considering that $e_{k}$ represents the controller input and $u_{k}$ its respective output, the recursive equation for computing the control signal is given by

$$
u_{k}=u_{k-1}+\left(K_{p x}+K_{i x}^{\prime}\right) e_{k}+\left(K_{i x}^{\prime}-K_{p x}\right) e_{k-1}
$$

where $K_{i x}^{\prime}=\frac{T_{s}}{2} K_{i x}$ and $k=1,2, \cdots$, denotes the $k^{t h}$ sampling instant.

\section{MOTOR CHARACTERIZATION}

The IPMS prototype cannot be considered as a standard synchronous motor. As emphasized in a preceding section the dynamic model of the IPMS prototype is similar in structure but substantially different from the standard Parks's model. In this case one must rely on experimental methods to determine the values for the model structure and its parameters.

\section{A. Magnet Flux Linkage}

To determine the magnetic flux linkage of IPMS prototype it has been operated as a generator driven by an auxiliary synchronous motor (AM) running at constant speed. Figure 7(a) illustrates the experimental set-up used in the characterization of the magnetic flux linkage; $v_{a b}$ and $n_{m}$ are acquired to characterize the magnetic flux linkage The waveform of one of the line to line voltages, $v_{a b}$, in open circuit, has been recorded as well as the speed of the auxiliary motor. Thus, the magnetic flux linkage can be determined by

$$
\lambda_{\mathrm{PM}}=\frac{60}{\pi n_{m}} \frac{1}{2 p} \frac{\max \left\{v_{a b}\right\}}{\sqrt{3}}
$$

where $\max \left\{v_{a b}\right\}$ denotes the amplitude of the line to line voltage $\left(v_{a b}\right)$ and $n_{m}$ denotes the speed of the auxiliary machine (in rpm) and $p$ is the number of pole pairs. Using this relationship and the dynamic model presented previously one may determine

$$
v_{d}=\omega_{r} \lambda_{r d}^{\prime}
$$

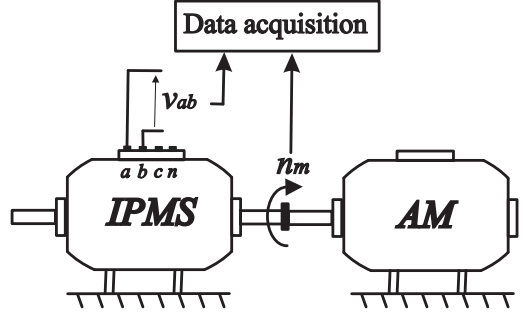

(a)

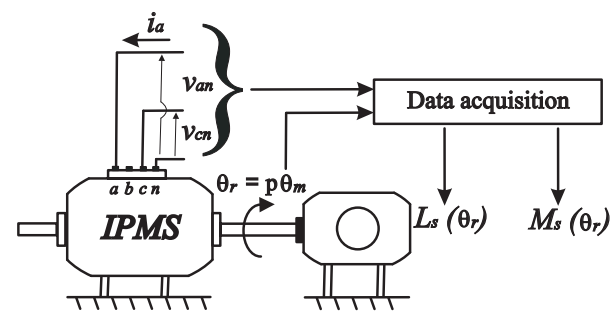

(b)

Fig. 7. Experimental arrangements used for characterizing the IPMS. a) Experimental arrangement used for determining the magnetic flux linkage of the IPMS prototype. b) Experimental arrangement for determining the self and mutual phase inductances.

and

$$
v_{q}=\omega_{r} \lambda_{r q}^{\prime}
$$

The refinement of the electromotive voltage representation is defined as a trade-off between accuracy and model complexity stated in terms of the quantity of harmonics.

\section{B. D- and Q-axis Inductances}

The first step for finding the $d$-axis and $q$-axis inductances is determining the self and mutual phase inductances $L_{s}\left(\theta_{r}\right)$ and $M_{s}\left(\theta_{r}\right)$. In the experimental test for determining the phase inductances the rotor of the IPMS prototype is mechanically locked at different angular positions. At each position one determines the phase impedance for calculating the self inductance and the induced voltage of an open phase for calculating the mutual inductance. Figure 7(b) illustrates the experimental set-up used in the characterization of the self and mutual phase inductances. The phase $a$ is excited with a sinusoidal voltage $v_{a n}$ (self inductance) and voltage at phase $c$ is used for measuring the induced voltage, $v_{c n}$ (mutual inductance). A milling dividing head is used to lock the rotor at a specific angular positions; in this test one needs to have access to the neural wire of the machine since the measurement of $v_{a n}$ and $v_{c n}$ are required.

The characterization procedure starts by applying a sinusoidal voltage to one of the phases and measuring the line current (flowing in this phase) and line voltage (one of the non excited phases). From these records one may determine the 
phase inductances by using:

$$
\begin{aligned}
\hat{L}_{s}\left(\theta_{r}\right) & =\frac{\sqrt{\left(\frac{\left|\overrightarrow{v_{a n}}\right|}{\left|\overrightarrow{i_{a}}\right|}\right)^{2}-r_{s}^{2}}}{2 \pi f_{e}} \\
\hat{M}_{s}\left(\theta_{r}\right) & =\frac{\left|\overrightarrow{v_{c n}}\right|}{2 \pi f_{e}\left|\overrightarrow{i_{a}}\right|}
\end{aligned}
$$

where $\theta_{r}$ is the electrical angle at which the measurement is taken, $\left|\overrightarrow{v_{a n}}\right|$ is the RMS value of the applied sinusoidal voltage, $\left|\overrightarrow{i_{a}}\right|$ is the RMS value of the line current, $f_{e}$ is the frequency of the applied sinusoidal voltage and $\left|\overrightarrow{v_{c n}}\right|$ is the induced voltage (at one of the non excited phases). These steps are repeated

$$
\forall \theta_{r} \in \Theta_{\mathrm{R}}, \Theta_{\mathrm{R}}=\left\{\theta_{1}, \theta_{2}, \cdots, \theta_{N}\right\}
$$

After measuring at all of these positions one has determined estimates for the angular profiles of the self and the mutual phase inductances, i.e.,

$$
\left\{\bar{L}_{s}\left(\theta_{r}\right), \bar{M}_{s}\left(\theta_{r}\right), \theta_{r} \in \Theta_{\mathrm{R}}\right\} .
$$

To use those estimates in the dynamic model one needs to decompose these profiles in terms of a Fourier series, i.e.:

$$
\begin{gathered}
\hat{L}_{s}\left(\theta_{r}\right)=L_{0}+\sum_{n=1}^{K_{L}} L_{n} \cos \left(2 n \theta_{r}\right) \\
\hat{M}_{s}\left(\theta_{r}\right)=M_{0}+\sum_{n=1}^{K_{M}} M_{n} \cos \left[2 n\left(\theta_{r}+\frac{\pi}{3}\right)\right] .
\end{gathered}
$$

This decomposition can be formulated as a system identification problem:

$$
\begin{gathered}
\hat{\mathfrak{L}}_{L}=\arg \min _{\mathfrak{L}_{L} \in D_{L}}\left[\bar{L}_{s}\left(\theta_{r}\right)-\hat{L}_{s}\left(\theta_{r}, \mathfrak{L}_{L}\right)\right]^{2} \\
\mathfrak{L}_{L}=\left[L_{0}, L_{n}, n=1, \cdots, K_{L}\right] \\
\hat{\mathfrak{L}}_{M}=\arg \min _{\mathfrak{L}_{M} \in D_{M}}\left[\bar{M}_{s}\left(\theta_{r}\right)-\hat{M}_{s}\left(\theta_{r}, \mathfrak{L}_{M}\right)\right]^{2} \\
\mathfrak{L}_{M}=\left[M_{0}, M_{n}, n=1, \cdots, K_{M}\right]
\end{gathered}
$$

which can be solved by using the least squares method, provided $K_{L}$ and $K_{M}$ are specified.

Since the experiment used to determine the phase inductance profiles was conducted at locked rotor, although at different positions, the mechanical speed is always zero, i.e., $\omega_{r}=0$. In this case the $d q$ voltage equations of the dynamic model can be simplified to

$$
v_{d}=r_{s} i_{d}+l_{d} \frac{d i_{d}}{d t}
$$

and

$$
v_{q}=r_{s} i_{q}+l_{q} \frac{d i_{q}}{d t}
$$

Then, assuming that

$$
\hat{L}_{s}\left(\theta_{r}\right)=L_{0}+\sum_{n=1}^{4} L_{n} \cos \left(2 n \theta_{r}\right)
$$

and

$$
\hat{M}_{s}\left(\theta_{r}\right)=M_{0}+\sum_{n=1}^{4} M_{n} \cos \left[2 n\left(\theta_{r}+\frac{\pi}{3}\right)\right]
$$

one may apply the coordinate transformation matrices to obtain, after some algebraic work [see $\mathbf{L}_{d q}$ the d- and q- axis inductances, $\mathbf{L}_{c}$ the coupling inductances given in (1), (8) and (9)], the following relationships:

$$
\begin{gathered}
L_{d}=L_{0}-M_{0}+\frac{1}{2} L_{1}+M_{1} \\
L_{q}=L_{0}-M_{0}-\frac{1}{2}-L_{1}-M_{1} \\
l_{d h}=\frac{1}{2} L_{2}+M_{2}+L_{3}-M_{3}+\frac{1}{2} L_{4}+M_{4} \\
l_{q h}=-\frac{1}{2} L_{2}-M_{2}+L_{3}-M_{3}-\frac{1}{2} L_{4}-M_{4} \\
l_{c d c}=L_{d}-L_{q}, l_{c a c}=-2 L_{2}-4 M_{2}+4 L_{4}+8 M_{4} .
\end{gathered}
$$

\section{Stator Resistance}

The experimental arrangement used for determining the self and mutual phase inductances has also been used to determine the stator resistance. Figure 8 shows a phasor diagram for which one may derive the following expression which was employed to calculate the stator resistance:

$$
r_{s}=\cos \left(\theta_{i a}\right) \frac{\left|\overrightarrow{v_{a n}}\right|}{\left|\overrightarrow{i_{a}}\right|}
$$

where, $\theta_{i a}$ is the angle between $v_{a n}$ and $i_{a}$. This technique includes sinusoidal excitation and skin effects.

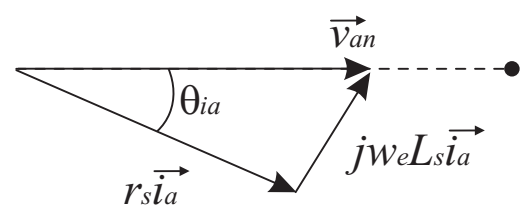

Fig. 8. Phasor diagram used to determine stator resistance.

\section{Parameter Estimation}

The techniques described previously have been applied to determine the parameters of the dynamic model of the IPMS prototype.

Magnetic flux linkage- Figure 9 shows the experimentally acquired line voltage (upper plot) observed as a result of the magnetic flux linkage when the auxiliary motor runs at $900 \mathrm{rpm}$. The line voltage is a highly distorted waveform and its relevant frequency content (lower plot) is also shown in the same figure. The harmonic orders and amplitudes are given in Table II. To decide how many harmonics must be included 


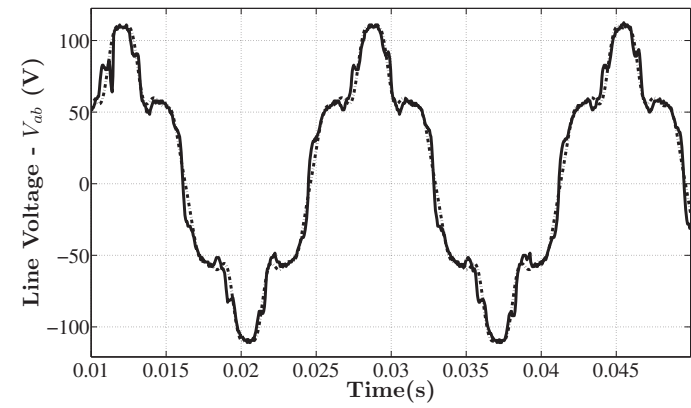

(a)

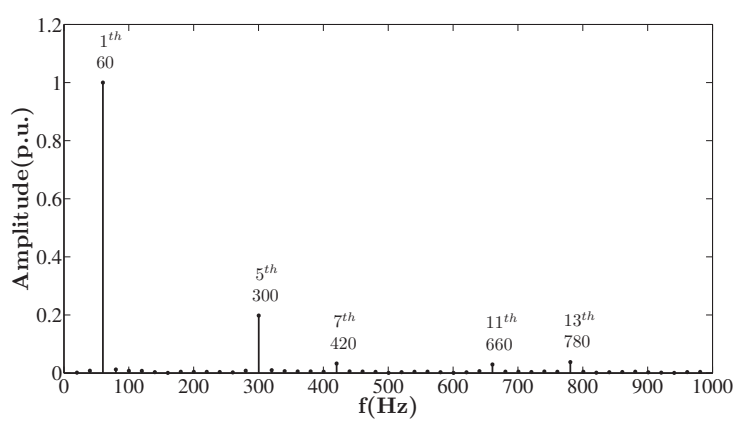

(b)

Fig. 9. Experimentally obtained $v_{a b}$ (thick line) (a) and its reconstructed version (dotted line) as obtained with the relevant frequency components (b) (see Table II).

\section{TABLE II}

Harmonic Orders and Amplitudes of $v_{a b}$ Waveform.

\begin{tabular}{cc}
\hline Harmonic order & Amplitude $(\mathrm{V})$ \\
\hline$c_{1}$ & 1.0 \\
\hline$c_{5}$ & 0.19797 \\
\hline$c_{7}$ & 0.032879 \\
\hline$c_{11}$ & 0.029614 \\
\hline$c_{13}$ & 0.037828 \\
\hline
\end{tabular}

in the representation of the line to line voltage, the reduction of approximation error (its RMS value) when more harmonics are added in the Fourier expansion was observed; no reduction in the error has been observed for harmonic order greater than 13. Based on these results one may determine the harmonic content of the magnetic flux linkage $\left(\lambda_{\mathrm{PM} i}=c_{i} \lambda_{\mathrm{PM}}\right)$ of the dynamic model of IPMS prototype as given in Table III.

$$
\begin{gathered}
\lambda_{\mathrm{PM}}=\sqrt{\frac{3}{2}} \lambda_{\mathrm{PM} 1} \\
\lambda_{\mathrm{PM} 6 d}=\sqrt{\frac{3}{2}}\left(\lambda_{\mathrm{PM} 5}-\lambda_{\mathrm{PM} 7}\right) \\
\lambda_{\mathrm{PM} 12 d}=\sqrt{\frac{3}{2}}\left(\lambda_{\mathrm{PM} 13}-\lambda_{\mathrm{PM} 11}\right) \\
\lambda_{\mathrm{PM} 6 q}=\sqrt{\frac{3}{2}}\left(\lambda_{\mathrm{PM} 5}+\lambda_{\mathrm{PM} 7}\right) \\
\lambda_{\mathrm{PM} 12 q}=\sqrt{\frac{3}{2}}\left(\lambda_{\mathrm{PM} 13}+\lambda_{\mathrm{PM} 11}\right) .
\end{gathered}
$$

TABLE III

Harmonic Orders, $d q$ Representation and Amplitudes for Representing the Magnetic Flux Linkage.

\begin{tabular}{cccc}
\hline Harmonic order & Amplitude $(\mathrm{Wb})$ & \multicolumn{2}{c}{$d q$-representation } \\
\hline$\lambda_{\mathrm{PM} 1}$ & 0.1333 & $\lambda_{\mathrm{PM} q}$ & 0.1633 \\
\hline$\lambda_{\mathrm{PM} 5}$ & 0.0259 & $\lambda_{\mathrm{PM} 6 d}$ & 0.0364 \\
\hline$\lambda_{\mathrm{PM} 7}$ & 0.0038 & $\lambda_{\mathrm{PM} 6 q}$ & 0.0271 \\
\hline$\lambda_{\mathrm{PM} 11}$ & 0.0032 & $\lambda_{\mathrm{PM} 12 d}$ & 0.0088 \\
\hline$\lambda_{\mathrm{PM} 13}$ & 0.0040 & $\lambda_{\mathrm{PM} 12 q}$ & -0.00097 \\
\hline
\end{tabular}

TABLE IV

Harmonic Components of the Self and Mutual Inductances.

\begin{tabular}{cc}
\hline \multicolumn{2}{c}{ Inductances. } \\
\hline Component & Inductance $(\mathrm{mH})$ \\
\hline$L_{0}$ & 9.51 \\
\hline$L_{1}$ & -5.72 \\
\hline$L_{2}$ & -0.52 \\
\hline$L_{3}$ & 1.03 \\
\hline$L_{4}$ & -0.076 \\
\hline$M_{0}$ & -1.88 \\
\hline$M_{1}$ & 1.03 \\
\hline$M_{2}$ & -1.08 \\
\hline$M_{3}$ & 0.32 \\
\hline$M_{4}$ & 0.11 \\
\hline
\end{tabular}

$d$-axis and $q$-axis inductances- Figure 10 shows $\left\{\bar{L}_{s}\left(\theta_{r}\right), \bar{M}_{s}\left(\theta_{r}\right), \theta_{r} \in \Theta_{\mathrm{R}}\right\}$ for $\Theta_{\mathrm{R}}=\{0, \cdots, 2 \pi\}$ as obtained experimentally. The phase current $i_{a}$ was kept at $2.5 \mathrm{~A}$ (RMS) $\forall \theta_{r} \in \Theta_{\mathrm{R}}$. Based on these profiles the least squares method was applied to determine the harmonic components of the self and mutual phase inductances. Similarly, to decide how many harmonics must be included in the representation of the self and mutual inductances profile, the reduction of approximation error (its RMS value) when more harmonics (increasing $K_{L}$ and $K_{M}$ ) are added in the Fourier expansion was observed; no reduction in the error has been observed for $K_{L}$ and $K_{M}$ greater than 4 . Table IV gives the amplitudes of the four components of the self and mutual inductances as well as its $d q$ representation. The thick lines in Figure 10 show the self and mutual inductances as calculated with these four harmonic terms.

Stator resistance- By applying the procedure described previously, the stator resistance was found to be $1.3915 \Omega$.

\section{MODEL VERIFICATION}

A model verification test is described in this section. The IPMS prototype was connected to a resistive bank of $33.33 \Omega / 150 \mathrm{~W}$ per phase and it has been driven by the auxiliary machine at a constant speed $(900 \mathrm{rpm})$. The same operating condition was simulated by using the estimated parameters (see Section V). Figure 11 shows the measured $\left(i_{m e s}\right)$ and calculated $\left(i_{c a l c}\right)$ phase current and the respective instantaneous error $\left(\varepsilon(k)=i_{\text {meas }}(k)-i_{\text {calc }}(k)\right)$.

The mean square error between the measured and calculated phase current has been computed. For each phase, the mean square error computed by

$$
\varepsilon_{L S}=\frac{1}{N} \sum_{k=1}^{N} \varepsilon(k)^{2}
$$

where $k$ is the sample number, $N$ the number of samples, $i_{\text {meas }}$ the measured phase current and $i_{\text {calc }}$ the respective 
TABLE V

Parameters of the IPMS Prototype.

\begin{tabular}{cc}
\hline Nominal speed $\left(n_{m}\right)$ & $900 \mathrm{rpm}$ \\
\hline$L_{d}$ & $9.55 \mathrm{mH}$ \\
\hline$L_{q}$ & $13.22 \mathrm{mH}$ \\
\hline$l_{d h}$ & $0.55 \mathrm{mH}$ \\
\hline$l_{q h}$ & $2.0 \mathrm{mH}$ \\
\hline$l_{c a c}$ & $5.9 \mathrm{mH}$ \\
\hline Stator resistance $\left(r_{s}\right)$ & $1.39 \Omega$ \\
\hline Moment of inertia $(J)$ & $0.00131 \mathrm{Kgf} / \mathrm{m}^{2}$ \\
\hline
\end{tabular}

calculated phase current. The magnitude of the mean square errors represent $0.57 \%, 0.52 \%, 0.59 \%$, of the amplitude of phase currents $i_{a}, i_{b}$, and $i_{c}$, respectively. Based on those results one may conclude that the model given by (1) can suitably be used to describe the dynamics of the IPMS.

\section{SIMULATION AND EXPERIMENTAL RESULTS}

Table $\mathrm{V}$ gives the parameters of the dynamic model of the IPMS prototype. A computational code based on the Runge-Kutta-Fehlberg integration method has been employed for simulating the motor drive system configuration described in Figure 4.

\section{A. Simulation Results}

Figure 12, 13, and 14 show the dynamic response of the motor drive system in terms of step changes in the reference speed with and without load. Table VI shows the gains of the discrete time equivalent (Tustin discretization method) of the current controller for three different conditions regarding the self inductance profile $l_{d, q}\left(\theta_{r}\right)$, i.e., the maximum $L_{d, q}+$ $l_{d h, q h}$, the dc component $L_{d, q}$ and the minimum $L_{d, q}-l_{d h, q h}$. As verified by simulation (the results are not shown due to space limitations) the response time of the closed-loop is fairly the same. Thus, instead of using current controllers with angle varying gains, it was decided to keep the gains constant and

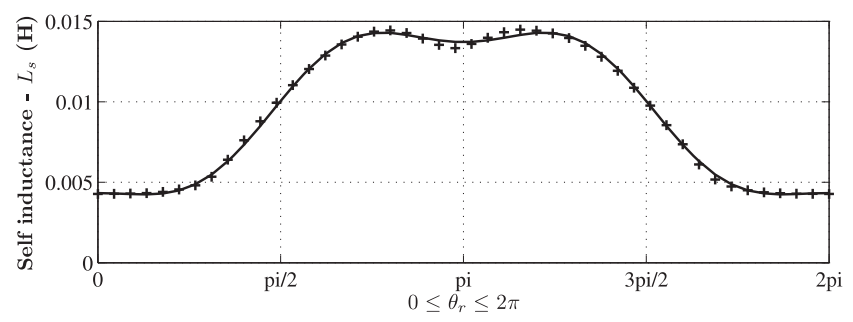

(a)

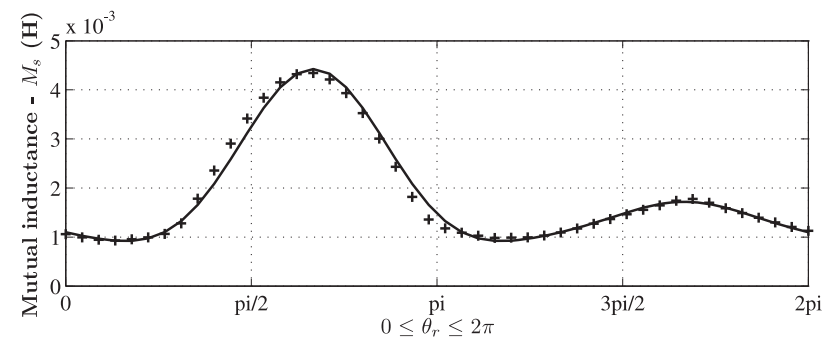

(b)

Fig. 10. Estimates of the angular profile of motor inductances: a) Self inductance and b) Mutual inductance.

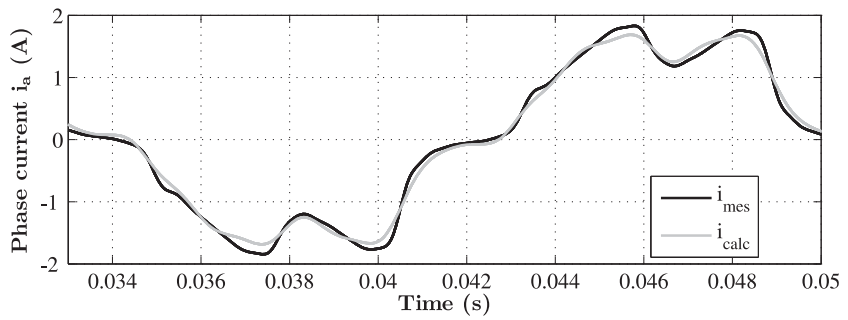

(a)

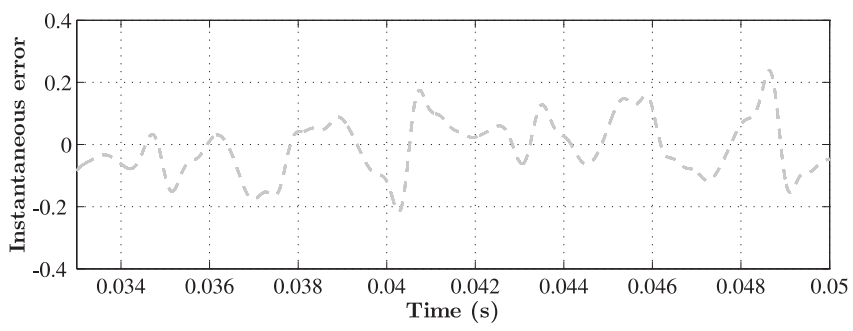

(b)

Fig. 11. Measured current, calculated current and phase current error. a) Measured and calculated currents an b) Instantaneous current error.

TABLE VI

Gains for the Discrete Time Representation of the Stator Current Controllers as Obtained by Applying the Tustin Discretization Technique for $T_{s}=100 \mu \mathrm{s}$.

\begin{tabular}{ccc}
\hline Inductance & $K_{p\{d, q\}}+K_{i\{d, q\}}^{\prime}$ & $-K_{p\{d, q\}}+K_{i\{d, q\}}^{\prime}$ \\
\hline$L_{d}-l_{d h}$ & 48.24 & -30.86 \\
\hline$L_{d}$ & 51.19 & -32.75 \\
\hline$L_{d}+l_{d h}$ & 54.13 & -34.63 \\
\hline$L_{q}-l_{q h}$ & 60.14 & -38.48 \\
\hline$L_{q}$ & 70.86 & -45.33 \\
\hline$L_{q}+l_{q h}$ & 81.58 & -52.19 \\
\hline
\end{tabular}

equal to the ones determined for the dc component of the self inductances. The decision has a beneficial impact on the realtime implementation since it allows to reduce the number of mathematical operations and consequently its complexity. The effect of compensating or not the back-emfs at the output of the current controllers, i.e., $\hat{u}_{d}$ and $\hat{u}_{q}$, respectively, is also shown (see Figure 12 and 13).

Figure 12 shows the dynamic response of the quadrature current control loop. The dashed black line denotes the reference $\left(i_{q}^{*}\right)$ and the solid gray line denotes the quadrature current $i_{q}$. From $t=0$ to $t=1.5 \mathrm{~s}$ there is no compensation for the back-emf term. Details of the response around the labels (a) and (b) are zoomed in Figure 12(a) and Figure 12(b), respectively; at label (a) the load $(1 \mathrm{Nm})$ is applied and at (b) the load is removed. Details of the response around the labels (c) and (d) are zoomed in Figure 12(c) and Figure12(d), respectively; at label (c) the load is applied and at (d) the load is removed. In this case, since the compensation for the backemf is provided (from $t=1.5 \mathrm{~s}$ to $t=3 \mathrm{~s}$ ) one can clearly see the improvement in terms of disturbance rejection.

Figure 13 shows the dynamic response of the speed control loop. The dashed black line denotes the reference $\left(n_{m}^{*}\right)$ and the solid gray line denotes the mechanical speed $\left(n_{m}\right)$. The period from $t=0.15 \mathrm{~s}$ to $t=0.5 \mathrm{~s}$ is the startup transient due 
to a step change of $900 \mathrm{rpm}$. Details of the response around labels (a) and (b) are zoomed in Figure 13(a) and Figure 13(b), respectively. At (a) the load $(1 \mathrm{Nm})$ is applied and at (b) the load is removed.

Figure 14 shows the dynamic response of $i_{q}, i_{d}$ and $n_{m}$ during a speed reversal. The reference speed set to $0 \mathrm{rpm}$ and at $t=0.1 \mathrm{~s}$ a $900 \mathrm{rpm}$ step change is applied. At $t=0.8 \mathrm{~s}$ the load $(1 \mathrm{Nm})$ is applied and at $t=1.2 \mathrm{~s}$ the load is removed. At $t=1.5 \mathrm{~s}$ the reference speed is changed to $-900 \mathrm{rpm}$. At $t=2.2 \mathrm{~s}$ the load $(1 \mathrm{Nm})$ is applied and at $t=2.5 \mathrm{~s}$ the load is removed.
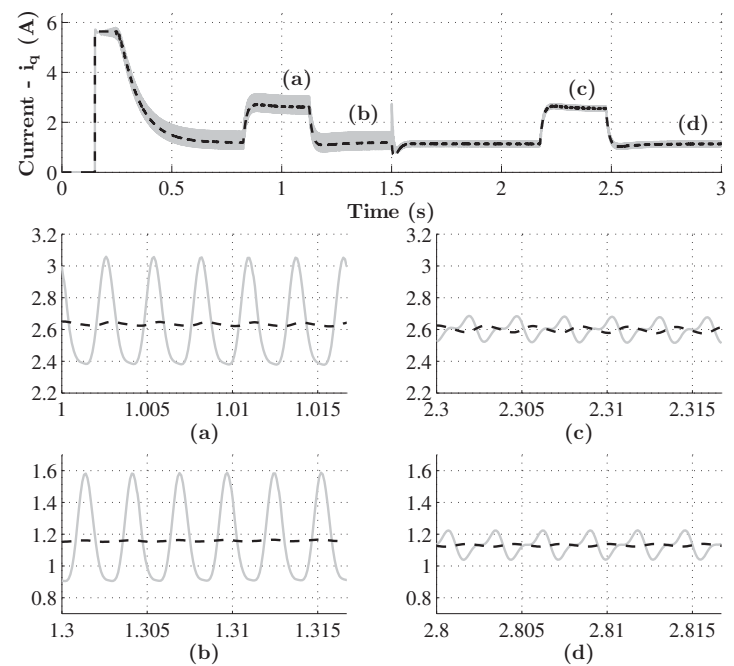

Fig. 12. Dynamic response of the quadrature current control loop.

\section{B. Experimental Results}

Figure 15 shows the experimental test platform. The same control system studied by simulation was tested by using this test platform. Discrete-time implementation of the controllers based on Tustin approximation has been employed for a sampling time of $100 \mu \mathrm{s}$. As indicated in block diagram the IPMS prototype has been fed through a PWMVSI switching at $10 \mathrm{kHz}$, synchronized with the sampling time. Fixed point arithmetic (Q31) has been used since the digital signal processor (DSP) does not have a floating point unit. Mechanical speed measurement has been obtained from a resolver and an auxiliary permanent magnet motor (AM) was used as the mechanical load for the IPMS prototype.

Figure 16, 17 and 18 show oscilloscope snapshot screens illustrating the dynamic response of the implemented system. The IPMS prototype motor is driven at rated speed in two test scenarios. For all the test scenarios, the motor drive control scheme is the one illustrated in Figure 4.

The results of the first experimental test are shown in Figure 16, i.e., a step change of the reference speed from 0 to $900 \mathrm{rpm}$, followed by the application of a mechanical load. The reference speed is set to $0 \mathrm{rpm}$ and at $t=0.7 \mathrm{~s}$ changed to $900 \mathrm{rpm}$ without load. Mechanical load $(1 \mathrm{Nm})$ is applied at $t=3.5 \mathrm{~s}$.

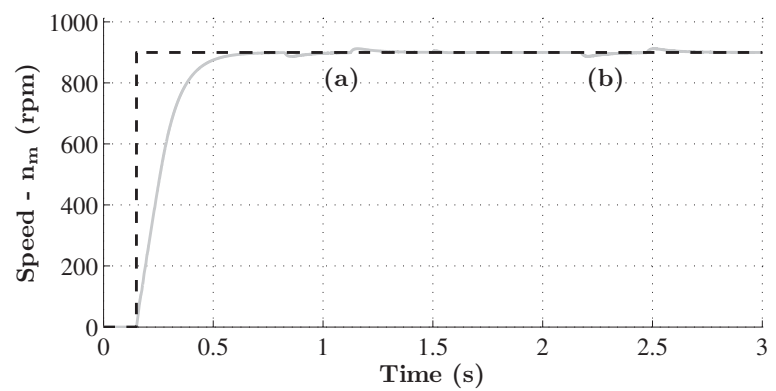

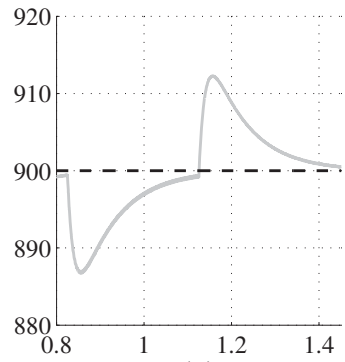

(a)

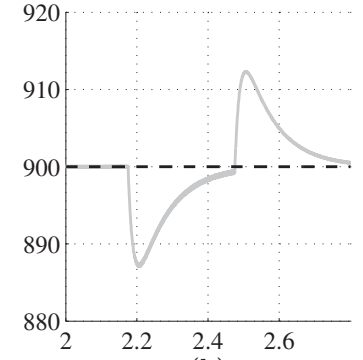

(b)
Fig. 13. Dynamic response of the speed control loop.
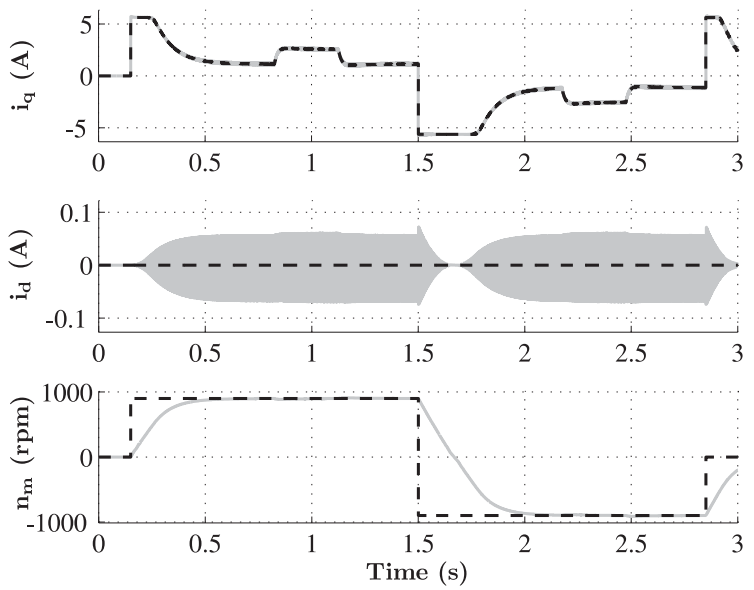

Fig. 14. Dynamic response of $i_{q}, i_{d}$ and $n_{m}$ during a speed reversal.

The results of the second test are shown in Figure 17, i.e., a speed reversal of the reference speed from $900 \mathrm{rpm}$ to $900 \mathrm{rpm}$. The reference speed is set to $0 \mathrm{rpm}$ and at $t=0.5 \mathrm{~s}$ changed to $900 \mathrm{rpm}$ without load. The speed reversal from $900 \mathrm{rpm}$ to $-900 \mathrm{rpm}$ is applied at $t=3 \mathrm{~s}$. It is important to note that these snapshots (upper and lower) have been obtained sequentially, since we used a two channels oscilloscope. Indeed, the first step change of the speed reference (lower plot) should coincide with the first step change of the q-axis current (upper plot). The two oscilloscope snapshot screens are displaced and thus when interpreting the results one must consider that curves of the upper plot $\left(i_{q}^{*}\right.$ and $\left.i_{q}\right)$ must be left 


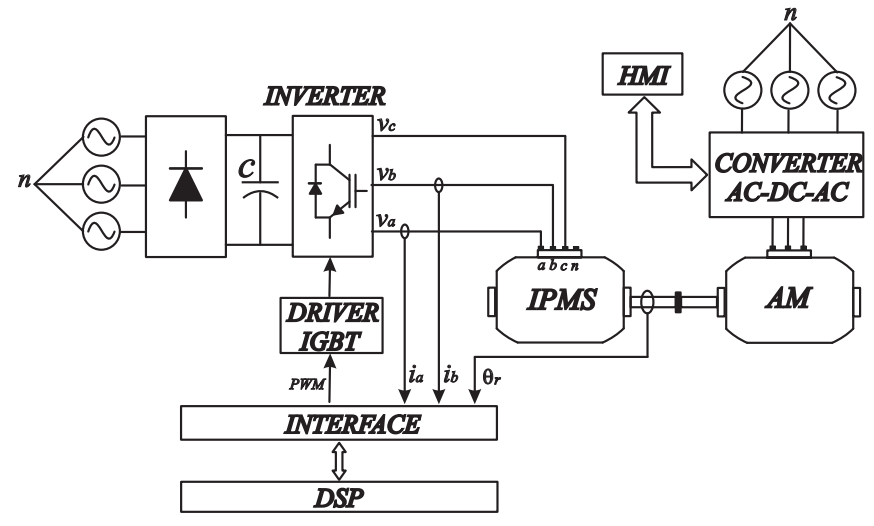

Fig. 15. Block diagram of the platform used in the first and second test scenarios.

\section{shifted by $500 \mathrm{~ms}$.}

Figure 18 shows the dynamic response of the $d$ and $q$-axis current controllers when the back-emfs are compensated. Those responses clearly indicate that the proposed methodology is cogent both in terms of the proposed dynamic model as well as in terms of control design procedure.

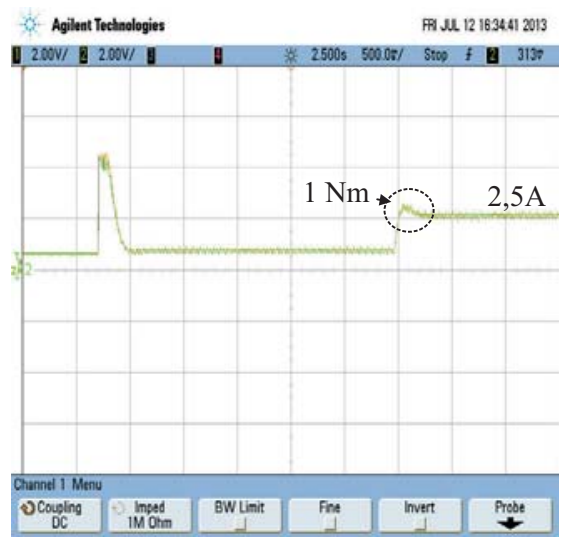

(a)

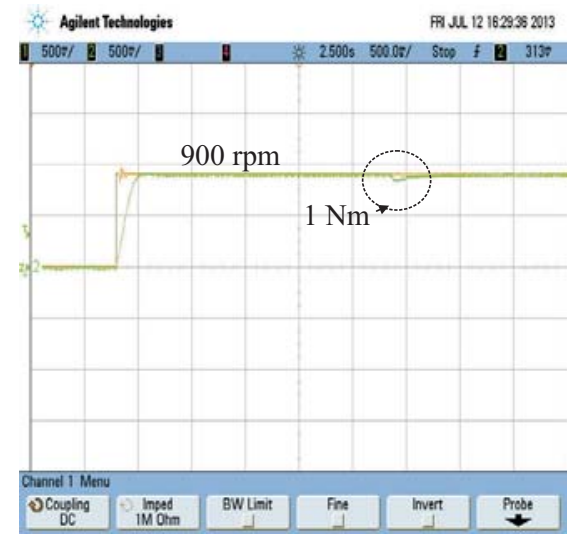

(b)

Fig. 16. First test scenario. The upper plot (a) shows the transient response for the current control loop. The lower plot (b) shows the dynamic response of the speed control loop.

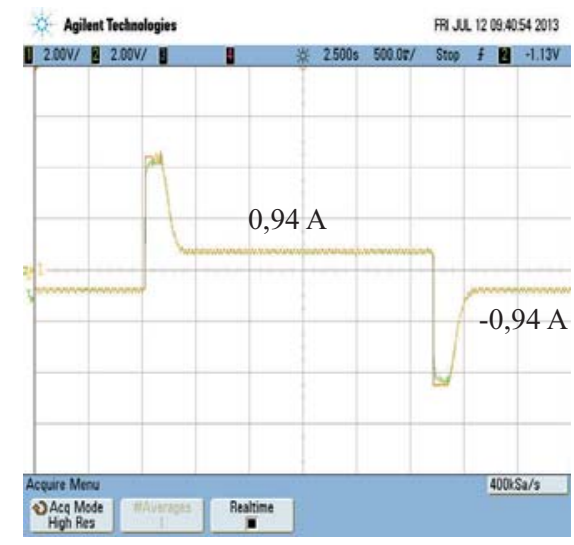

(a)

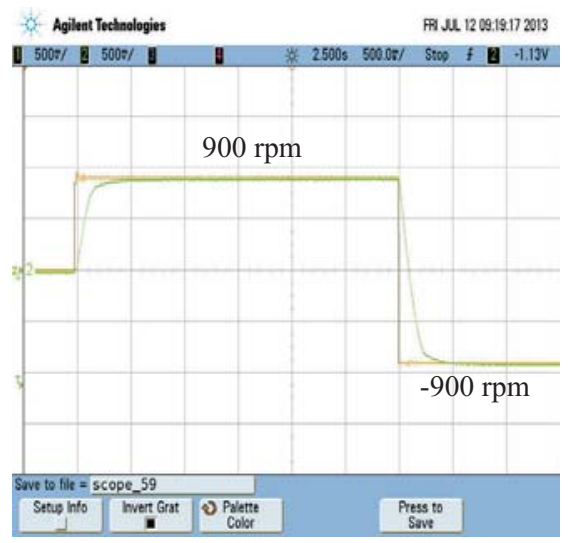

(b)

Fig. 17. Second test scenario. The upper plot (a) shows the $q$-axis current. The lower plot (b) shows the dynamic response of the speed control loop.

\section{CONCLUSION}

Low cost high performance permanent magnet motor drive system can be achieved with low energy density magnets by exploiting the flux concentration configuration. The electromagnetic configuration demand quite important changes in the standard Park's model to represent the dynamics of the IPSM prototype. The agreement between the results obtained by numerical simulation and the experimental ones demonstrates the validity of the proposed methodology in terms of the proposed dynamic model, the parameter estimation technique, the control design procedure and realtime implementation strategy. Finally, the results obtained so far clearly demonstrates the feasibility of proposed motor design, model verification and its related control strategy. The use of constant gain current controllers was evaluated numerically and tested experimentally to demonstrate its effectiveness. Besides this, these results also show that the standard cascade strategy is quite robust, providing a good motor drive performance at all the experimental test conditions so far. Further investigation regarding the operational limits, ripple torque minimization, sensorless operation, angular position control and nonlinear characteristics is underway. The application of the proposed modeling and control methodology to an IPMS in which the polar pieces have been 


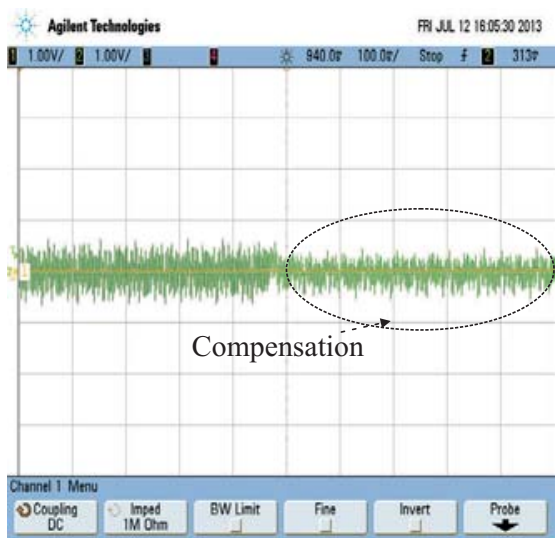

(a)

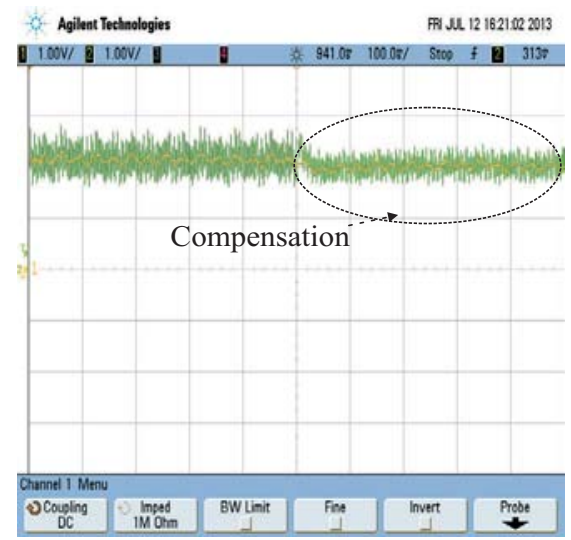

(b)

Fig. 18. Back-emf compensation. The upper plot (a) shows the $d$-axis current without and with back-emf compensation. The lower plot (b) shows the $q$-axis current without and with back-emf compensation. In both case the back-emf compensation is applied at $t=0.5 \mathrm{~s}$.

modified to minimize the cogging torque is also a subject for further studies.

\section{ACKNOWLEDGEMENT}

The authors would like to thank PPgEE/UFCG, CAPES and $\mathrm{CNPq}$ for the financial support and research grants.

\section{REFERENCES}

[1] A. Vagati, G. Pellegrino, P. Guglielmi, "Comparison between SPM and IPM motor drives for EV application," in XIX International Conference on Electrical Machines, pp. 1-6, 2010.

[2] K. Bourzac, The rare-earth crisis, MIT Technology Review, pp. 1-7, April/2011.

[3] K. Yamamoto, K. Shinohara, "Comparison between space vector modulation and subharmonic methods for current harmonics of DSP-based permanent-magnet AC servo motor drive system," IEE Proceedings Electric Power Applications, vol. 143, no. 2, pp. 151-156, Mar/1996.

[4] C.B. Butt, M. Ashraful Hoque, M.A. Rahman, "Simplified Fuzzy-Logic-Based MTPA Speed Control of IPMSM Drive," IEEE Transactions on Industry
Applications, vol. 40, no. 6, pp. 1529-1535, NovemberDecember/2004.

[5] M.N. Uddin, T.S. Radwan, G.H. George, M.A. Rahman, "Performance of current controllers for VSI-fed IPMSM Drive," IEEE Transactions on Industry Applications, vol. 36, no. 6, pp. 1531-1538, October/2000.

[6] J.-H. Seo, D.-K. Woo, T.-K. Chung, H.-K. Jung, “A Study on Loss Characteristics of IPMSM for FCEV Considering the Rotating Field," IEEE Transactions on Magnetics, vol. 46, no. 8, pp. 3213-3216, August/2010.

[7] K.-C. Kim, D.-H. Koo, J.-P. Hong, J. Lee, “A Study on the Characteristics Due to Pole-Arc to Pole-Pitch Ratio and Saliency to Improve Torque Performance of IPMSM," IEEE Transactions on Magnetics, vol. 43, no. 6, pp. 2516-2518, June/2007.

[8] B.-H. Lee, S.-O. Kwon, T. Sun, J.-P. Hong, G.-H. Lee, J. Hur, "Modeling of Core Loss Resistance for dq Equivalent Circuit Analysis of IPMSM considering Harmonic Linkage Flux," IEEE Transactions on Magnetics, vol. 47, no. 5, pp. 1066-1069, May/2011.

[9] E.R. Braga Filho, Contribuição ao estudo e projeto de máquinas síncronas a imãs permanentes para geração eólica e redução do conteúdo harmônico do fluxo indutor, Doctoral dissertation, Campina Grande, 2011.

[10] B.J. Chalmers, S.A. Hamed, G.D. Baines, "Parameters and performance of a high-field permanent-magnet synchronous motor for variable-frequency operation," IEE Proceedings B Electric Power Applications, vol. 132, no. 3, pp. 117-124, May/1985.

[11] C.-S. Jin, D.-S. Jung, K.-C. Kim, Y.-D. Chun, H.-W. Lee, J. Lee, "A Study on Improvement Magnetic Torque Characteristics of IPMSM for Direct Drive Washing Machine," IEEE Transactions on Magnetics, vol. 45, no. 6, pp. 2811-2814, June/2009.

[12] J.F. Gieras, E. Santini, M. Wing, "Calculation of synchronous reactances of small permanent-magnet alternating-current motors: comparison of analytical approach and finite element method with measurements," IEEE Transactions on Magnetics, vol. 34, no. 5, pp. 3712 -3720, September/1998.

[13] M.A.A. Costa, Caracterização e controle de um motor síncrono a imãs interiores, Master's thesis, Campina Grande, 2013.

[14] U. Schaible, B. Szabados, "Dynamic motor parameter identification for high speed flux weakening operation of brushless permanent magnet synchronous machines," IEEE Transactions on Energy Conversion, vol. 14, no. 3, pp. 486-492, September/1999.

[15] A. Cavagnino, M. Lazzari, F. Profumo, A. Tenconi, "Axial flux interior PM synchronous motor: parameters identification and steady-state performance measurements," IEEE Transactions on Industry Applications, vol. 36, no. 6, pp. 1581-1588, NovemberDecember/2000.

[16] S.-B. Lee, "Closed-Loop Estimation of Permanent Magnet Synchronous Motor Parameters by PI Controller Gain Tuning," IEEE Transactions on Energy Conversion, vol. 21, no. 4, pp. 863 -870, December/2006. 
[17] R. Dutta, M.F. Rahman, “A Comparative Analysis of Two Test Methods of Measuring d- and q-Axes Inductances of Interior Permanent-Magnet Machine," IEEE Transactions on Magnetics, vol. 42, no. 11, pp. 3712 -3718, November/2006.

[18] J.-Y. Lee, S.-H. Lee, G.-H. Lee, J.-P. Hong, J. Hur, "Determination of parameters considering magnetic nonlinearity in an interior permanent magnet synchronous motor," IEEE Transactions on Magnetics, vol. 42, no. 4, pp. 1303 -1306, April/2006.

[19] S. Yamamoto, T. Ara, K. Matsuse, "A Method to Calculate Transient Characteristics of Synchronous Reluctance Motors Considering Iron Loss and CrossMagnetic Saturation," IEEE Transactions on Industry Applications, vol. 43, no. 1, pp. 47-56, JanuaryFebruary/2007.

[20] P. Niazi, H.A. Toliyat, "Online Parameter Estimation of Permanent-Magnet Assisted Synchronous Reluctance Motor," IEEE Transactions on Industry Applications, vol. 43, no. 2, pp. 609-615, March-April/2007.

\section{BIOGRAPHIES}

Marcos Aurélio Araujo Costa was born in Teresina, Piauí, Brazil, in 1984. He received the Bachelor's and Master's degrees in electrical engineering from Universidade Federal de Campina Grande, Campina Grande, Paraíba, Brazil. He is currently a doctorate student at the Universidade Federal de Campina Grande, and his research interests are in the field of electrical machines and drive systems.
Edgar Roosevelt Braga-Filho He has a Bachelor degree in electrical engineering from Universidade Federal da Paraíba. He received his doctoral degree in electrical engineering from the Universidade Federal de Campina Grande. He is currently a faculty member of the Department of Electrical Engineering of the Universidade Federal de Campina Grande, and his research interests are in field of electrical machines and drive systems.

Antonio Marcus Nogueira Lima was born in Recife, Pernambuco, Brazil, in 1958. He received the Bachelor's and Master's degrees in electrical engineering from Universidade Federal da Paraíba - UFPB, Campina Grande, Paraíba, Brazil in 1982 and 1985, respectively. He received his doctoral degree in electrical engineering in 1989 from Institut National Polytechnique de Toulouse - INPT, Toulouse, France. He was with the Escola Técnica Redentorista - ETER, Campina Grande, Paraíba, Brazil from 1977 to 1982 and was a Design Engineer at Sul-América Philips, Recife, Pernambuco, Brazil, from 1982 to 1983. From 1983 to March 2002 he was with the Electrical Engineering Department of UFPB where he became Full Professor in 1996. At UFPB he was Coordinator of Graduate Studies from 1991 to 1993 and from 1997 to 2002. Since April 2002 he has been with the Department of Electrical Engineering of the Universidade Federal de Campina Grande where he is currently Full Professor at the Department of Electrical Engineering. His current research interests are in the fields of electrical machines and drive systems, industrial automation, embedded systems, electronic instrumentation, control systems and system identification. 